\title{
Kadından Erkeğe Transeksüelizmde Fasiyal Kontur Uygulaması: Bir Olgu Sunumu
}

\author{
Facial Contour Operations For Female To Male Transexulism: A Case Report
}

\section{Mert Demirel, Savaş Serel}

Ankara Üniversitesi Tıp Fakültesi Plastik,Rekonstrüktifve Estetik Cerrahi Anabilim Dalı
Başvuru tarihi: 13.02.2010 • Kabul tarihi: 25.10.2010

\section{Iletişim}

Dr.Mert Demire

Ankara Üniversitesi Tıp Fakültesi Cebeci Araştırma ve Uygulama Hastanesi Plastik,Rekonstrüktif ve Estetik Cerrahi Anabilim Dalı 06100 Dikimevi / ANKARA

Telefon : 03125956175

E-Posta Adresi : mertdemireltr@yahoo.com

Kadından erkeğe transeksüelizm ülkemizde nadir görülen klinik durumlardandır. Buna rağmen kliniğimizde az da olsa bu tip vakalarla karşılaşmaktayız. Bu hastaların en belirgin dilekleri genital seksüel rekonstrüksüyonlarıdır. Bu işlemleri mastektomi operasyonları ve kontur düzeltme operasyonları takip eder. Bu olgu sunumunda genital rekonstrüksüyonu ve meme cerrahisi tamamlanmış 32 yaşında bir bayan hasta incelenmiştir. Kliniğimizde bu hastanın fasiyal kontur onarımlarına yönelik girişimler yapılmış ve hastanın isteğine göre bir sonuca ulaşıımıştır. Erkeksi bir yüz bölgesi yaratmak için dikkat edilmesi gereken noktalar mevcuttur. Kavisi olmayan bir burun dorsumu, belirgin çene ucu ve mandibular köşe, belirgin supraorbital bölge bunlardan bazılarıdır. Bu çalışmamızda bir kadından erkeğe transeksüelizm vakasında fasiyal bölge kontur uygulamaları gözden geçirilmiştir.

Anahtar Sözcükler: Transeksüelizm, Yağ enjeksiyonu, Medpor

From women to men transexualism is a rare clinical condition in Turkey. However, in our clinic we face these kind of cases rarely. Most prominent wishes of these patients are genital sexual reconstruction. Mastectomy operations and contour correction operations will follow it. In this case a 32 year-old female(male) patient whose genital and breast surgery reconstructions have been completed, was examined. In our clinic attempts were made to repair the facial contour, and a conclusion was reached based on the patient's request. To create a masculine face, there are some dots to be considered. A non- arc nasal dorsum, distinctive chin and mandibular corner, prominent supraorbital region are some of them. In this study we rewieved facial region contour applications for female to male transxual cases.

Key Words: Transexualism, Lipoinjection, Medpor

32 yaş bayan hasta kliniğimize fasiyal bölgesinin erkek cinsine daha çok benzemesi için başvurdu. Başka bir klinikte penis rekonstrüksüyonu ve mastektomi operasyonları birkaç seans halinde yapılmıştı. Hastanın sağlık kurulu raporu değerlendirildi ve psikiyatri konsültasyonu yapıldı. Hasta ile tartışarak ne gibi değişikliklerin yapılacağın karar verildi. Hastaya belirgin ve köşeli bir çene konturu sağlamak için rektangular medpor implantı, kavisli ve feminen görünümdeki burun dorsumunu düzeltmek için kıkırdak grefti ile hafif bir hump şekillendirmesi ve derin ve erkeksi bir bakış için kaş altına yağ enjeksiyonu yapılması planlandı. Operasyon tek seansta ve komplikasyonsuz olarak gerçekleştirildi (Şekil 1,2,3,4).

\section{Tartışma}

Erkeksi yüz isteği tanımlaması zor bir sorundur. Erkeksi bir yüzün ne gibi özellikler taşıması gerektiği kurallar ile belirlenmiş bir olay değildir. Kuralları olmadığı gibi çağlar ve kültürlere bağlı olarak ta değişiklik gösterebilir. Biz yaşadığımız yüzyıl ve içinde bulunduğumuz özellikler göz önüne alınarak bir takım öneriler getirdik. Bunun için "erkek" ve "yakışıklı" olarak bilinen bir takım meşhur kişilerin fotoğraflarını inceledik. Bütün resimlerde en çok göze batan ve ortak yanları tanımlamaya çalıştık (Şekil 5, 6, 7). İnsanların neye göre çekici veya yakışıklı olduğunu anlamaya yönelik bir çok çalışma mevcuttur. Bir çoğunda alt yüz oranının üst tarafa göre daha büyük olan insanların daha çekici olduğunu belirtmektedir. Ayrıca köşeli çene yapısı 


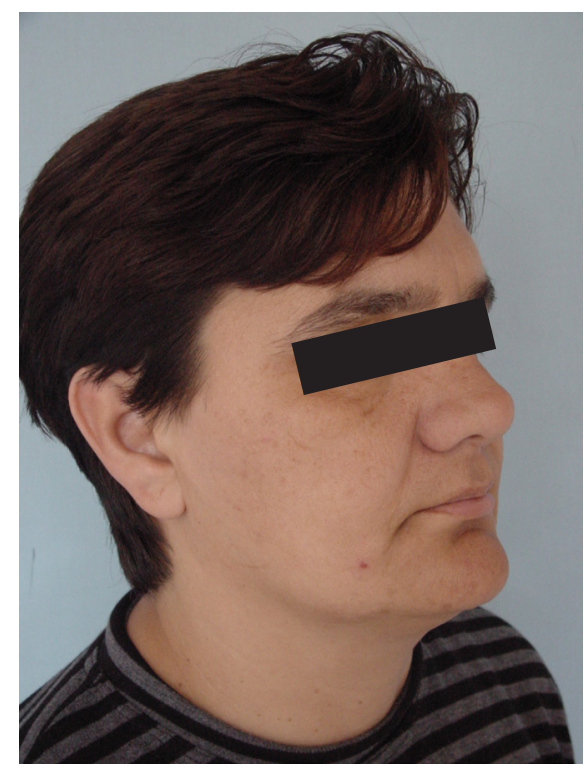

Şekil 1: Hastanın sol oblik preoperatif görüntüsü

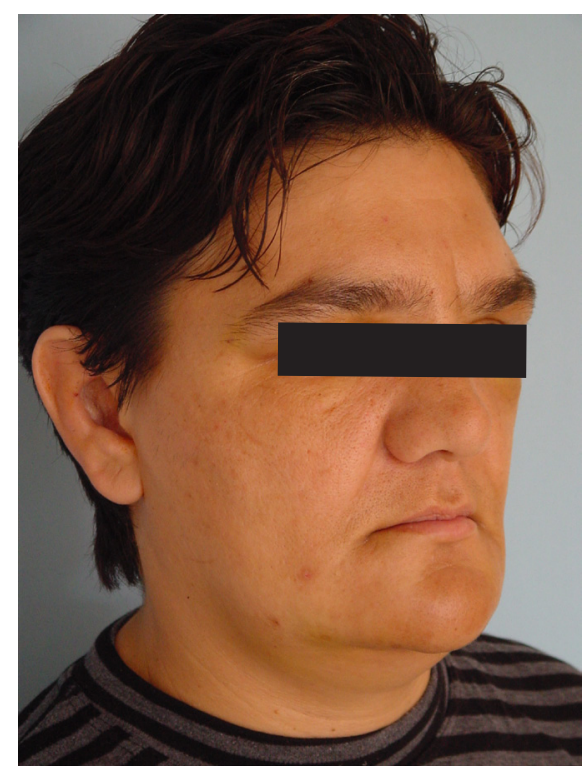

Şekil 3: Hastanın sol oblik postoperatif görüntüsü

da diğerlerine göre daha çekici olduğu belirtilmektedir $(1,2)$.

Hastanın öne doğru çıkık ince bir çene ucu mevcuttu. Labiomental sulkusu oldukça belirgindi. Ayrıca aşağı doğru sarkmış yanak bölgesiyle üzgün ve yaşlı bir ifadesi vardı. Bu deformitenin giderilmesi için Rektangular biçimli Medpor implantı uygulaması seçildi. Mandibula korpusuna periost altına uygulanmasıyla, labiomental sulkus belirginliği azaldı, çene ucu geniş ve güçlü bir görünüme sahip oldu. Medpor fasial bölge kontur restorasyonları

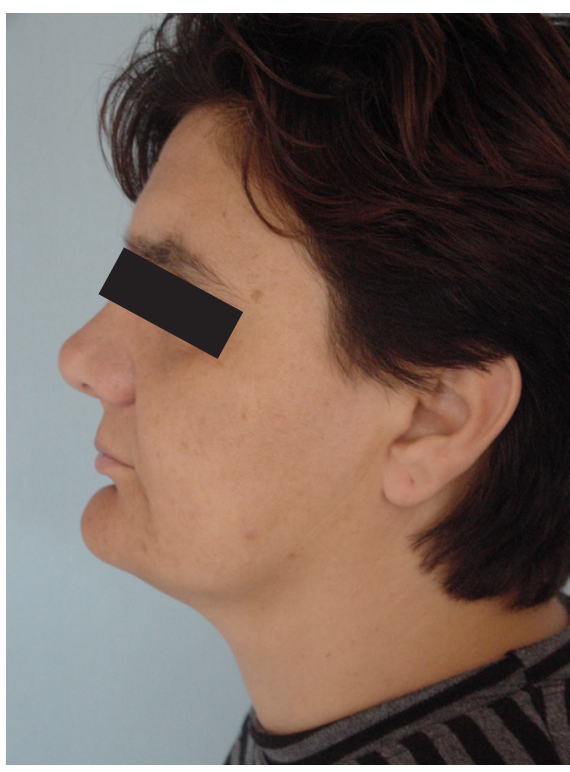

Şekil 2: Hastanın sağ lateral preoperatif görüntüsü

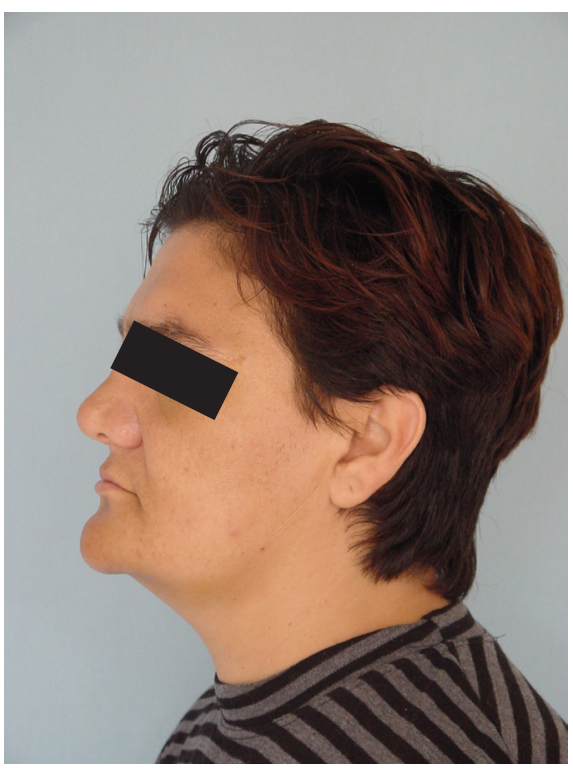

Şekil 4: Hastanın sağ lateral postoperatif görüntüsü

için çok uzun süredir güvenle kullanılan bir alloplastik materyaldir(3).

Lateral bakışta en çok göze batan oluşumlardan biri de burun dorsumunun oldukça feminen kavislenmesiydi. Burun dorsumunu biraz olsun düz hale getirmek için alloplastik bir madde yerine otojen bir doku kullanılmasına karar verildi. Bunun için kosta grefti ya da kulak kıkırdak grefti seçenekleri hastaya sunuldu. Hasta tercihine göre kulaktan kıkırdak grefti alındı ve sağ alt lateral kıkırdağın üst sınırından burun ciltaltına ulaşıldı. Açılan tünelden

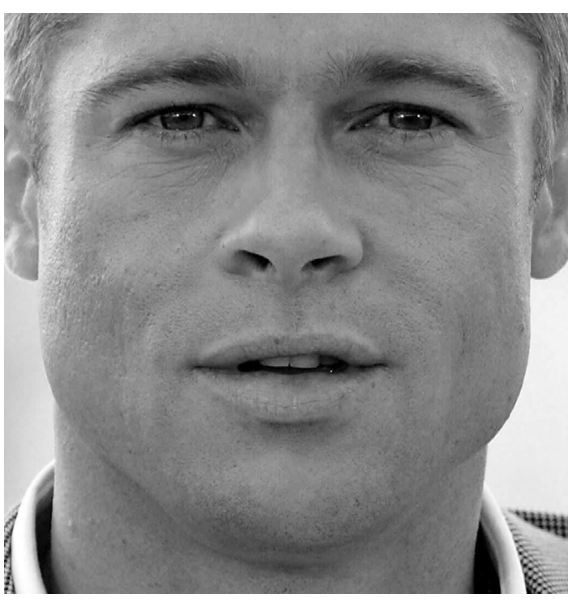

Şekil 5: Meşhur sinema yıldızının en belirgin özelliği mandibula açısının belirgin olmasıdır. Bu yüzüne "kaslı" ve güçlü bir imaj vermektedir. Ayrıca düz burun dorsumu da bu görünümü desteklemektedir. Kaş çıkıntısının belirgin olması sanatçıya derinden bakıyor görünütüsü vererek daha etkileyici kılmaktadır.

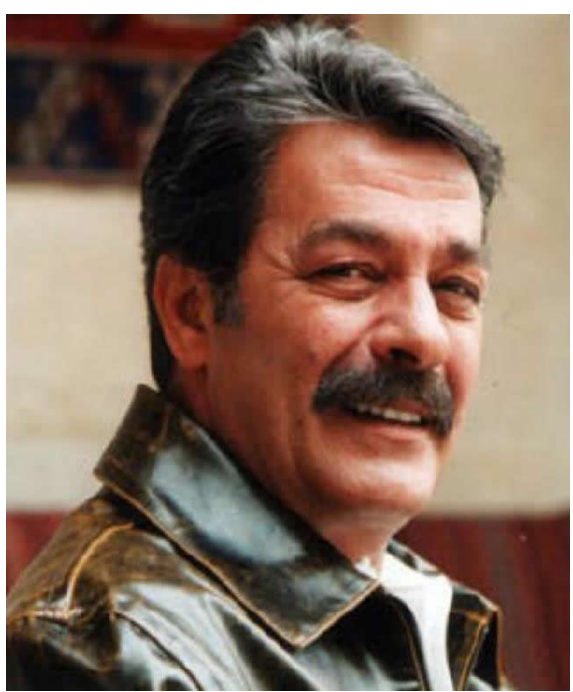

Şekil 6: Türk sinema yıldızının horizontal planda geniş duran mandibula korpusu ve köşeli yüzü sert imajına katkıda bulunmaktadır.

ilerletilen greft materyali dişarıdan uygulanan atel yardımıyla sabitlendi. $\mathrm{Bu}$ yöntem kullanılan maddenin otojen olması nedeniyle seçilmiştir. Bu bölgeye uygulanan alloplastik maddelerin rejeksiyonuna sık rastlanılmaktadır(4).

Hastanın her ne kadar kaş bölgesi çıkıntısı belirgin olsa bile daha da belirginleştirmek için kaş altına yağ enjeksiyonu yapıldı. Kaşların biraz daha arasını açıp feminen görüntüyü arttırmamak için mümkün mertebe glabellar bölgeye yapılmamaya çalışıldı. Yağ enjeksiyonları uzun yıllardır plastik cerrahide kullanılan bir yöntemdir (5). Konvan- 
siyonel metotlarla uygulanacağı gibi, büyüme faktörleriyle ya da fiziksel bir takım prosedürlerle zenginleştirilerek de kullanılmaktadır (6,7).Büyük bir kısmı 6 aylık bir sürede makrofajlar tarafından ortamdan uzaklaştırılmak$\operatorname{tad} ı r(8)$. Bu bölgenin hataya ve beğeniye açık bir bölge olmasından dolayı, kısmen geri dönüşlü olduğu için bu alanda yă̆ enjeksiyonu yapılmasına karar verildi. Yağ enjeksiyonu; hem fasiyal kontur restorasyonunda estetik amaçli(5), hem de çeşitli endikasyonlarda rekonstrüksüyon amaçlı kullanılmaktadır $(9,10)$.

\section{Sonuç}

Kıl folikülünden yoğun bir yanak ve çene bölgesi, açıları dik ve belirgin çene ke- mikleri, derin ve sert görünümlü bakış, düz kavissiz bir burun dorsumu; "maskülen” fenotip için ortak özellikler olarak kabul edilmiştir. Seçtiğimiz vakada bu ortak özellikleri uygulamaya çalıştık. Bu özelliklerin yaratılması için otojen ya da alloplastik olarak çeşitli seçenekler mevcuttur. Seçeneklerimizi tanıyabilmek ve ön görümüzü arttırabilmek için önceden yapılmış vakalar ve alloplastik implant katalogları iyi değerlendirilmelidir. Bu konuda çalışırken her hastanın farklı ihtiyaçları olacağından, hastanın çekilmiş preoperatif fotoğraflarıyla beraber, seçenekler ayrıntılı anlatılarak çalışılmasında fayda olacağını savunuyoruz.

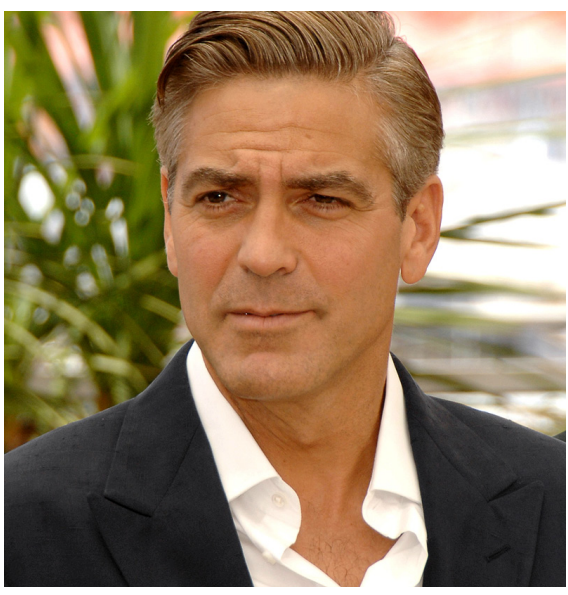

Şekil 7: Meşhur sinema yıldızının alt dudağı ile mentumu arasındaki uzun mesafe oyuncuya "erkeksi" bir hava vermektedir. Ayrıca kıl folikülünden yoğun yüzü bu havayı artırmaktadır

\section{KAYNAKLAR}

1. Naini FB, Cobourne MT, McDonald F, Donaldson AN.The influence of craniofacial to standing height proportion on perceived attractiveness. Int J Oral Maxillofac Surg. 2008 Oct;37(10):877-85

2. Johnston DJ, Hunt O, Johnston CD, Burden DJ, Stevenson M, Hepper P.Eur J Orthod. The influence of lower face vertical proportion on facial attractiveness. 2005; Aug;27(4):349-54

3. Gui L, Huang L, Zhang Z.Genioplasty and chin augmentation with Medpore implants: a report of 650 cases. Aesthetic Plast Surg. 2008 Mar;32(2):220-6.

4. Oztürk S, Sengezer M, Coskun U, Zor F An unusual complication of a Medpor implant in nasal reconstruction: a case report.. Aesthetic Plast Surg. 2002 NovDec;26(6):419-22
5. Guerrerosantos J. Long-term outcome of autologous fat transplantation in aesthetic facial recontouring: sixteen years of experience with 1936 cases. Clin Plast Surg. 2000 Oct;27(4):515-43.

6. Yoshimura K, Asano Y, Aoi N, et al.Progenitor-Enriched Adipose Tissue Transplantation as Rescue for Breast Implant Complications. Breast J. 2009 Nov 12.

7. Yoshimura K, Sato K, Aoi N, et al. Cell-assisted lipotransfer for facial lipoatrophy: efficacy of clinical use of adipose-derived stem cells. Dermatol Surg. 2008 Sep;34(9):117885

8. Bartynski J, Marion MS, Wang TD.Histopathologic evaluation of adipose autografts in a rabbit ear model. Otolaryngol Head Neck Surg. 1990 Apr;102(4):314-21
9. Giugliano C, Benitez S, Wisnia P, Sorolla JP, Acosta S, Andrades P. Liposuction and lipoinjection treatment for congenital and acquired lipodystrophies in children. Plast Reconstr Surg. 2009 Jul;124(1):134-43

10. Yu-Feng L, Lai G, Zhi-Yong Z. Combined treatments of facial contour deformities resulting from Parry-Romberg syndrome. J Reconstr Microsurg. 2008 Jul;24(5):333-42. 